\title{
Fusion versus fixation in complex comminuted C3-type tibial pilon fractures: a systematic review
}

\author{
Yash P. Chaudhry ${ }^{1}$, Efstratios Papadelis ${ }^{1}$, Hunter Hayes ${ }^{1}$, Philip F. Stahel ${ }^{2}$ and Erik A. Hasenboehler ${ }^{3 *}$ (D)
}

\begin{abstract}
Background: Comminuted intra-articular tibial pilon fractures can be challenging to manage, with high revision rates and poor functional outcomes. This study reviewed [1] treatment, complications, and clinical outcomes in studies of complex comminuted tibial pilon fractures (type AO43-C3); and [2] primary ankle arthrodesis as a management option for these types of complex injuries.
\end{abstract}

Methods: A systematic literature search was performed on PubMed from 1990 to 2020 to determine complications and outcomes after staged fracture fixation and primary ankle joint arthrodesis for comminuted C3-type tibial pilon fractures.

The search was conducted in compliance with the PRISMA guidelines, using the following MeSH terms: "tibial pilon"/"pilon fracture"/"plafond fracture"/"distal tibial"/"43-C3"/"ankle fracture"/"ankle fusion"/"primary ankle arthrodesis"/"pilon fracture staged"/"pilon external fixation" and "pilon open reduction internal fixation." Inclusion criteria were restricted to original articles in English language on adult patients $\geq 18$ years of age. Eligibility criteria for retrieved publications were determined using a "PICO" approach (population, intervention/exposure, comparison, outcomes). Weighted analysis was used to compare treatment groups on time to definitive treatment, follow-up time, range of motion, fracture classification, and complications.

Results: The systematic literature review using the defined MeSH terms yielded 72 original articles. Of these, 13 articles met the eligibility criteria based on the PICO statements, of which 8 publications investigated the outcomes of a staged fixation approach in 308 cumulative patients, and 5 articles focused on primary ankle arthrodesis in 69 cumulative patients. For staged treatment, the mean wound complication rate was $14.6 \%$, and the malunion/ nonunion rate was $9.9 \%$. For primary arthrodesis, the mean wound complication rate was $2.9 \%$, and the malunion/ nonunion rate was $2.9 \%$. After risk stratification for fracture type and severity, the small cumulative cohort of patients included in the primary arthrodesis publications did not provide sufficient power to determine a clinically relevant difference in complications and long-term patient outcomes compared to the staged surgical fixation group.

\footnotetext{
* Correspondence: eahtrauma@icloud.com

${ }^{3}$ Department of Orthopaedic Surgery, The Johns Hopkins University, Johns Hopkins Bayview Medical Center, 4940 Eastern Ave. \#A667, Baltimore, MD 21224, USA

Full list of author information is available at the end of the article
}

(C) The Author(s). 2021 Open Access This article is licensed under a Creative Commons Attribution 4.0 International License, which permits use, sharing, adaptation, distribution and reproduction in any medium or format, as long as you give appropriate credit to the original author(s) and the source, provide a link to the Creative Commons licence, and indicate if changes were made. The images or other third party material in this article are included in the article's Creative Commons licence, unless indicated otherwise in a credit line to the material. If material is not included in the article's Creative Commons licence and your intended use is not permitted by statutory regulation or exceeds the permitted use, you will need to obtain permission directly from the copyright holder. To view a copy of this licence, visit http://creativecommons.org/licenses/by/4.0/ The Creative Commons Public Domain Dedication waiver (http://creativecommons.org/publicdomain/zero/1.0/) applies to the data made available in this article, unless otherwise stated in a credit line to the data. 
Conclusions: At present, there is insufficient evidence in the published literature to provide guidance towards consideration of ankle arthrodesis for complex comminuted C3-type tibial pilon fractures, compared to the standard treatment by staged surgical fracture fixation.

Keywords: Tibial pilon fracture, Primary ankle arthrodesis, Staged surgical fixation, Patient outcomes, Post-traumatic osteoarthritis, Complications

\section{Background}

Tibial pilon fractures are complex injuries that typically result from high-energy trauma mechanisms, e.g. axial compression or shearing injuries from motor vehicle accidents or falls from heights [1]. Accounting for less than $10 \%$ of all tibial fractures $[2,3]$, they can be challenging to manage because of the reconstruction needed of the involved articular surface and adjacent metaphysis and fibula fracture which is observed in up to $85 \%$ of cases.

Several classification systems allow comparison among different series and help guide clinical decision making. The AO/OTA Classification system $[4,5]$ is the most comprehensive system for categorizing pilon fractures, organizing them according to the degrees of articular surface involvement and comminution [6, 7]. Type AO 43-C3 fractures, which have a high degree of comminution and extensive intra-articular involvement, are the most challenging because of the severe disruption to the articular surface and the associated soft tissue injury [3, 8-11].

Studies $[1-3,8,12]$ have shown that complications and outcomes are closely associated with the degree of injury, especially that of soft tissues. Therefore, the goal of treatment is not only to stabilize the fracture and reduce the joint anatomically, but to preserve the soft tissue envelope [1-3, 8]. This concept has led to recommendations of a staged procedure especially for high-energy $\mathrm{AO} 43-\mathrm{C} 2$ and $\mathrm{AO} 43-\mathrm{C} 3$ injuries; initial external fixation (with or without internal fixation of the fibula) to allow soft tissue resting followed by open reduction and internal fixation (ORIF) 10 to 14 days later [10-15].

Regardless of the fixation method used to treat pilon fractures, a substantial percentage of patients develop complications postoperatively, including wound infection, osteomyelitis, nonunion, and post-traumatic osteoarthritis (PTOA) [10]. Although operative techniques and complication rates in pilon fractures have improved, the reported complication rates may lead to the erroneous conclusion that the outcomes for these injuries are substantially better than what is experienced clinically. These complications have the potential to result in long hospital stays, need for additional surgeries (e.g., secondary arthrodesis), prolonged pain control, nonweightbearing periods and absence from work.
The hypothesis of the present study was to review the literature of the past 30 years to assess treatment modalities, complications, and clinical outcomes for AO 43-C3 tibial fractures treated with a staged approach, versus primary arthrodesis to compare the outcomes between these 2 patient populations and to determine if primary arthrodesis can be a definitive treatment option for these fractures.

\section{Methods \\ Literature review process}

This study was conducted in accordance with the Preferred Reporting Items for Systematic Reviews and Meta-Analyses (PRISMA) guidelines [16]. The authors searched the PubMed database for articles from January 1990 through June 2020 containing any of the following MeSH terms or combinations thereof: "tibial pilon," "pilon fracture," "plafond fracture," "distal tibial," "43-C3," "ankle fracture," "ankle fusion," "primary ankle arthrodesis," "pilon fracture staged," "pilon external fixation," and "pilon open reduction internal fixation." Studies were considered eligible and included in the review if they met the following criteria, designed through the population, intervention/exposure, comparison, and outcome (PICO) approach [17]:

1. Population: adult patients who underwent surgery for AO 43-C3 tibial pilon fractures

2. Intervention/Exposure: randomized controlled trials (RCTs), prospective cohort studies, and retrospective cohort studies examining outcomes of operative fixation of $\mathrm{AO} 43-\mathrm{C} 3$ tibial pilon fractures with either staged treatment or primary arthrodesis

3. Comparison: outcomes for patients receiving staged treatment versus primary arthrodesis

4. Outcomes: outcome measures included rates of malunion, nonunion, wound infection, pain from implant, development of PTOA, amputation, secondary ankle arthrodesis, as well as ankle range of motion

\section{PICO question 1}

In adult patients with $\mathrm{AO}$ 43-C3 type tibial pilon fractures, should primary arthrodesis be performed (versus staged treatment) to decrease rates of short-term complications in the form of malunion, nonunion, wound infection, and hardware-related pain? 


\section{PICO question 2}

In adult patients with $\mathrm{AO} 43-\mathrm{C} 3$ type tibial pilon fractures, should primary arthrodesis be performed (versus staged treatment) to decrease rates of long-term complications in the form of development of PTOA, requirement for amputation or secondary ankle arthrodesis, and improved ankle range of motion?

Other exclusion criteria included animal and in vitro studies, articles published in languages other than English, case reports and case series of fewer than 5 patients, studies that used the Ruedi-Allgower [18] rather than the AO classification system, articles that pooled their data without clearly distinguishing among specific outcomes of different fracture patterns, and articles missing clear outcome parameters or follow-up information.

Abstracts and full-text manuscripts were screened and reviewed by three authors independently (YPC, HH, EP). Any discrepancies found were resolved by cross review and discussion among the authors until consensus was reached.

\section{Risk of Bias assessment}

The risk of bias was assessed within each study using the methodological index for non-randomized studies (MINORS) criteria [19]. The MINORS criteria is graded on a scale of 16 for noncomparative studies and 24 for comparative studies, and has demonstrated good testretest reliability and internal consistency in the examination of non-randomized studies in meta-analyses and systematic reviews [19].

\section{Statistical analysis}

The authors classified treatment groups in the included studies according to the use of fusion procedures. Five studies [8, 20-23] used fusion procedures, 8 studies used other types of treatment [3, 15, 24-29] (Table 1). Weighted analysis, using sample sizes reported in each article, was used to compare these 2 patient groups on key indices. These indices were time to definitive treatment, follow-up time, range of motion, fracture classification (fracture type and open vs closed), and presence of complications.

\section{Results}

The PICO questions addressed in this study were to evaluate the effectiveness of primary arthrodesis as a treatment option in $\mathrm{AO}$ 43-C3 type tibial pilon fractures as an alternative to staged treatment in reducing the rates of postoperative short-term complications and poor long-term outcomes. The initial MeSH keyword search yielded 72 original articles, 29 of which were eliminated based on the exclusion criteria (Fig. 1). The full-length manuscripts of the remaining 43 articles were included for review. None of the 43 articles had complete information in all the PICO categories investigated (Table 1). For articles reporting a staged surgical fixation approach, the most common reason for exclusion from the final review was the lack of differentiation in reported outcomes with regard to AO-OTA fracture type and status of the skin (open vs closed fractures), which accounted for the exclusion of 30 articles. In these articles, the outcomes were reported as the total number of the complication of interest for 1 treatment group compared with another treatment group, but without distinction as to whether the complication occurred in AO 43-C1 or AO 43-C3 injury or the status of the skin at the time of injury. The remaining 13, with 8 articles reporting a staged approach $[3,15,24-29]$ and 5 articles pertaining to primary arthrodesis $[8,20-23]$ were evaluated and analyzed. The 13 studies examined in this review included 377 total fractures, 228 of which involved AO 43-C3 pilon fractures.

Compared with cases treated without fusion, those treated with fusion had a significantly lower proportion of $\mathrm{C} 1 / \mathrm{C} 2$ fractures $(P<.001)$, but a higher proportion of C3 fractures $(92.8 \%$ vs. $53.2 \%)(P<.001)$. The fusion cohort also had a significantly higher period of follow-up $(P=.013)$ (Table 2$)$. There were no statistically significant differences between these two cohorts with regards to time to definitive treatment $(P=.063)$ or proportion of open fractures $(P=.594)$. None of the 13 studies examined all the assessed variables in this review. Only one of the studies was a comparative study [23], the rest were case series.

\section{PICO question 1: short-term complications}

Twenty-seven cases from the reviewed studies involved the development of malunion/nonunion and 49 involved wound problems/infection or pain from implant. The fusion cohort had a significantly lower proportion of cases involving wound issues or symptomatic hardware $(P=.049)$, but no significant differences were observed in the rates of malunion/nonunion between the two cohorts $(P=.085)$.

\section{PICO question 2: long-term complications}

Forty cases were noted to have developed PTOA; however all of these were observed in the staged treatment cohort as this was not recorded for any of the arthrodesis cases reviewed. Three cases involved the need for subsequent amputation of the affected extremity during the follow-up period; all three were in the staged treatment cohort as well ( $0.08 \%$ incidence).

\section{Risk of Bias assessment}

Of the noncomparative studies, the mean MINORS score was 10.2 (standard deviation 1.7). The single comparative study by Beckwitt et al. had a MINORS score of 
Table 1 Studies of AO-43C Tibial Pilon Fractures Treated with Primary Arthrodesis or Staged Treatment Using the AO/Orthopedic Trauma Association Classification System

\begin{tabular}{|c|c|c|c|c|c|c|c|c|c|c|c|c|c|}
\hline \multirow[t]{2}{*}{ Study } & \multirow[t]{2}{*}{ Treatment } & \multirow{2}{*}{$\begin{array}{l}\text { Mean } \\
\text { Time to } \\
\text { Definitive } \\
\text { Treatment } \\
\text { (d) }\end{array}$} & \multirow[t]{2}{*}{$\operatorname{Fxs}(n)$} & \multicolumn{2}{|c|}{$\begin{array}{l}\text { AO/OTA } \\
43 \mathrm{Fx} \\
\text { Type } \\
\text { (N) }\end{array}$} & \multirow{2}{*}{$\begin{array}{l}\text { Open } \\
\text { Fxs } \\
\text { (n) }\end{array}$} & \multicolumn{3}{|c|}{ Complications } & \multirow{2}{*}{$\begin{array}{l}\text { Amp } \\
\text { (n) }\end{array}$} & \multirow{2}{*}{$\begin{array}{l}\text { Mean } \\
\text { ROM } \\
\left({ }^{\circ}\right)\end{array}$} & \multirow{2}{*}{$\begin{array}{l}\text { Secondary } \\
\text { Fusion }(n)\end{array}$} & \multirow{2}{*}{$\begin{array}{l}\text { Mean } \\
\text { Follow- } \\
\text { up } \\
(\mathrm{mo})\end{array}$} \\
\hline & & & & $\begin{array}{l}\mathrm{C} 1 / \\
\mathrm{C} 2\end{array}$ & $\mathrm{C3}$ & & $\begin{array}{l}\mathrm{MU} / \\
\mathrm{NU} \\
\text { (n) }\end{array}$ & $\begin{array}{l}/ \\
1 / P \\
(n)\end{array}$ & $\overline{\operatorname{PTOA}(n)^{a}}$ & & & & \\
\hline $\begin{array}{l}\text { Beaman } \\
\text { and } \\
\text { Gellman } \\
{[20]}\end{array}$ & $\begin{array}{l}\text { Temporary ex fix followed by } \\
\text { primary arthrodesis }\end{array}$ & 15 & 12 & 0 & 12 & 5 & 0 & 1 & $\mathrm{NR}$ & 0 & $\mathrm{NR}$ & 0 & 24 \\
\hline $\begin{array}{l}\text { Borens } \\
\text { et al. [3] }\end{array}$ & $\begin{array}{l}\text { 2-Staged, minimally invasive } \\
\text { anterior approach }\end{array}$ & 11.3 & 17 & 9 & 8 & 3 & 0 & 6 & 8 & 0 & 30 & 1 & 17 \\
\hline $\begin{array}{l}\text { Bozic et al. } \\
{[8]}\end{array}$ & $\begin{array}{l}\text { Temporary ex fix followed by } \\
\text { primary arthrodesis }\end{array}$ & 140 & 15 & 0 & 15 & 8 & 0 & 1 & NR & 0 & NR & 0 & 39 \\
\hline $\begin{array}{l}\text { Grose et al. } \\
\text { [28] }\end{array}$ & 2-Staged, lateral approach & NR & 43 & 8 & 27 & 18 & 4 & 9 & NR & 0 & 43 & 0 & 13.7 \\
\hline $\begin{array}{l}\text { McCann } \\
\text { et al. [29] }\end{array}$ & Primary ORIF or 2-staged & 13.6 & 48 & 29 & 6 & 3 & 1 & 9 & 5 & NR & NR & NR & 9.1 \\
\hline $\begin{array}{l}\text { Morgan } \\
\text { et al. [21] }\end{array}$ & $\begin{array}{l}\text { Temporary ex fix followed by } \\
\text { late primary arthrodesis }\end{array}$ & 280 & 6 & 0 & 5 & 4 & 0 & 0 & NR & 0 & NR & 0 & 35 \\
\hline \multirow[t]{2}{*}{$\begin{array}{l}\text { Sirkin } \\
\text { et al.(15) }\end{array}$} & $\begin{array}{l}\text { 2-Staged, ex fix followed by } \\
\text { ORIF (closed) }\end{array}$ & 12.7 & 22 & 14 & 42 & 22 & NR & 6 & NR & 0 & NR & 0 & NR \\
\hline & $\begin{array}{l}\text { 2-Staged, ex fix followed by } \\
\text { ORIF (open) }\end{array}$ & 14 & 34 & & & 34 & NR & 4 & NR & 1 & NR & 1 & NR \\
\hline $\begin{array}{l}\text { Zelle et al. } \\
\text { [22] }\end{array}$ & $\begin{array}{l}\text { Temporary ex fix followed by } \\
\text { primary arthrodesis }\end{array}$ & 22 & 20 & 4 & 16 & 5 & 1 & 1 & NR & 0 & NR & 0 & 86 \\
\hline $\begin{array}{l}\text { Guan et al. } \\
\text { [25] }\end{array}$ & 2-staged & 19 & 13 & 0 & 13 & 3 & 2 & 0 & NR & NR & 28 & NR & 32 \\
\hline $\begin{array}{l}\text { Chen et al. } \\
\text { [24] }\end{array}$ & $\begin{array}{l}\text { 3-staged (ex fix, ORIF posterior } \\
\text { column, ORIF anterior/medial } \\
\text { columns) }\end{array}$ & 12 & 25 & 0 & 25 & 3 & 0 & 2 & 2 & NR & NR & 0 & 24.4 \\
\hline $\begin{array}{l}\text { Wang et al. } \\
{[26]}\end{array}$ & $\begin{array}{l}\text { Temporary ex fix followed by } \\
\text { ORIF (vacuum sealing } \\
\text { drainage) }\end{array}$ & 14.3 & 16 & 6 & 10 & $N R$ & 0 & 0 & 0 & 0 & $\mathrm{R}$ & $N R$ & 23.3 \\
\hline $\begin{array}{l}\text { Leonetti } \\
\text { et al. [27] }\end{array}$ & Ex fix vs. ORIF & NR & 71 & 9 & 14 & 20 & 13 & 9 & 14 & $N R$ & NR & $N R$ & 36 \\
\hline $\begin{array}{l}\text { Beckwitt } \\
\text { et al. [23] }\end{array}$ & $\begin{array}{l}\text { Primary ORIF and primary } \\
\text { arthrodesis }\end{array}$ & NR & 35 & 0 & 35 & 9 & 6 & 1 & 11 & $N R$ & NR & 1 & 73.7 \\
\hline $\begin{array}{l}\text { Total or } \\
\text { weighted } \\
\text { mean }\end{array}$ & & 16.1 & 377 & 79 & 228 & 103 & 27 & 49 & 40 & 3 & 37.3 & 3 & 33.2 \\
\hline
\end{tabular}

Amp, amputation; FXs, fractures; ex fix, external fixation; MU/NU, malunion, nonunion; NR, not reported; ORIF, open reduction and internal fixation; ROM, range of motion; W/I/P, wound problem, infection, or pain from implant

a Symptomatic or radiographic

${ }^{\mathrm{b}}$ Two fracture groups reported separately-closed and open-with 56 fractures in 53 patients

19. Results of the MINORS scoring is summarized on Table 3.

\section{Discussion}

Tibial pilon fractures resulting from high-energy mechanisms typically involve substantial comminution and soft tissue injury. Over the years, several treatment methods have been used for the management of these fractures [30-32]. Although there is no standardized method of fixation [33], most surgeons favor a staged approach to allow resolution of soft tissue swelling, which typically involves temporary ankle-bridging external fixation with or without fibular internal fixation followed by definitive ORIF [8, 10-15]. The current study's aim was to determine, on the basis of a review of the current literature, whether primary ankle arthrodesis is a reasonable alternative treatment choice to staged ORIF for AO43-C3 fractures. Although our qualitative synthesis demonstrated no differences in any of the observed 


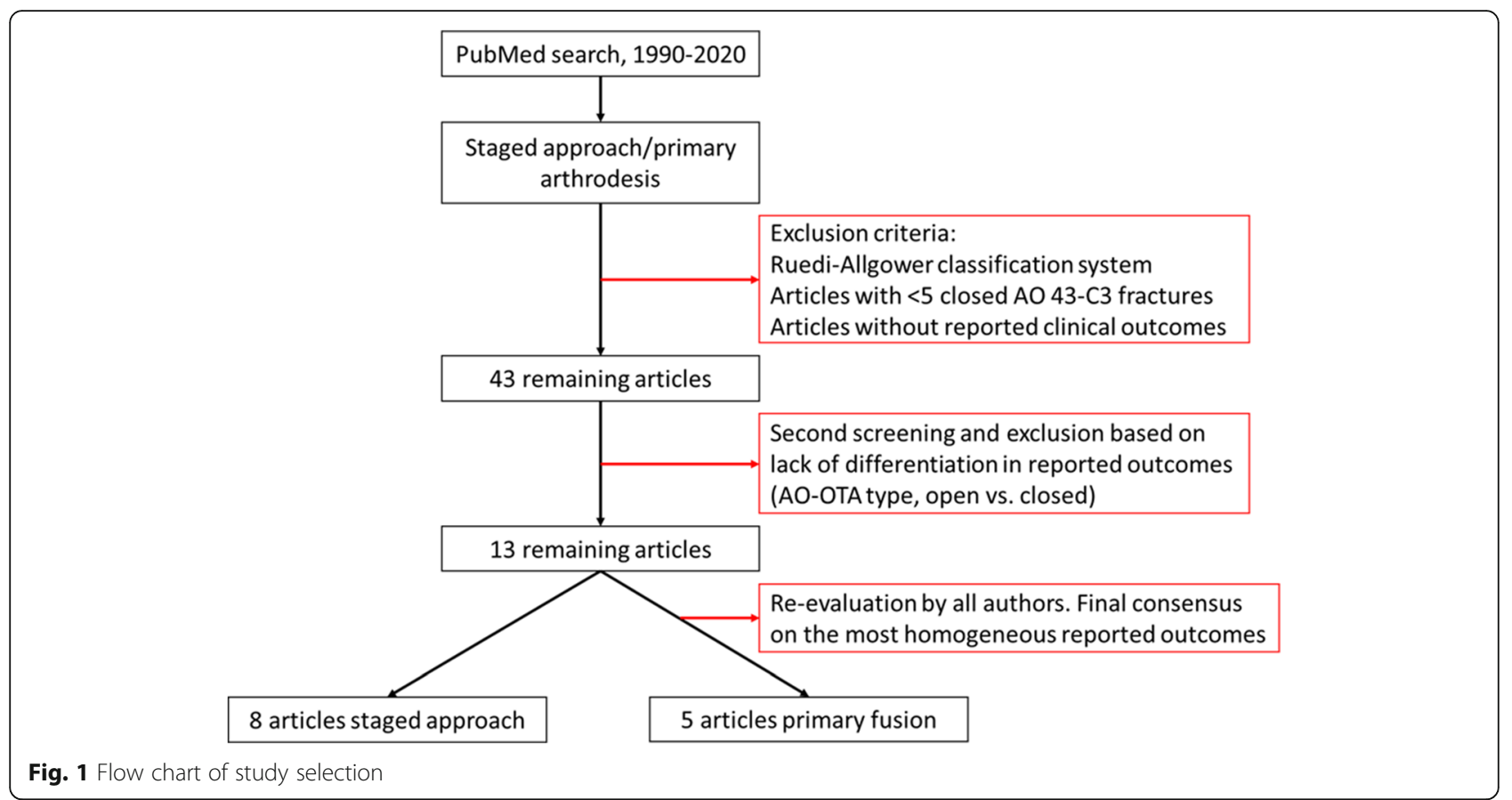

outcomes other than a tendency towards decreased shortterm complications (wound complications, infection, or hardware pain) with arthrodesis, there was insufficient evidence to allow for any definitive conclusion. The authors found that there are relatively few quality data reported in the literature regarding the management of $\mathrm{AO} 43-\mathrm{C} 3$ fractures. None of the studies reviewed had complete data, there was a lack of homogeneity in outcomes reporting, and most studies did not adequately distinguish among fracture types or report complete data on complications. Additionally, data on primary ankle arthrodesis are limited compared with staged ORIF and with all of these articles reporting only relatively small numbers of cases.

\section{PICO question 1: short-term complications}

Using primary arthrodesis for severely comminuted pilon fractures is not a novel concept. Beckwitt et al. examined the differences in patient outcomes between primary arthrodesis and primary ORIF in $\mathrm{AO}-43 \mathrm{C} 3$ pilon fractures and found that patients treated with the arthrodesis approach had a lower rate of nonunion [23]. While this study was notable in that the average follow-up was 73.7 months, like the other studies included in this review, it did not have a treatment arm involving staged treatment (primary ORIF was the comparator group). Zelle et al. [22] assessed 20 patients who underwent blade plate ankle

Table 2 Comparison of primary arthrodesis and staged treatment for AO 43-C Tibial Pilon Fractures

\begin{tabular}{|c|c|c|c|}
\hline & $\begin{array}{l}\text { Primary Arthrodesis } \\
\text { ( } n=69 \text { patients) }\end{array}$ & $\begin{array}{l}\text { Staged Treatment } \\
(n=308 \text { patients })\end{array}$ & $P$ Value \\
\hline Number of publications & 5 & 8 & N/A \\
\hline Time to definitive treatment, days ${ }^{a}$ & $82.02(44.48)$ & $13.58(0.68)$ & .063 \\
\hline Follow-up time, months ${ }^{\mathrm{a}}$ & $59.82(11.85)$ & $25.89(5.45)$ & .013 \\
\hline Range of motion, degrees ${ }^{a}$ & NA & $37.30(2.44)$ & N/A \\
\hline Open fracture ${ }^{b}$ & 39.1 & 37.8 & .594 \\
\hline \multicolumn{4}{|l|}{ Complications } \\
\hline Malunion/non-union ${ }^{\mathrm{b}}$ & 2.9 & 9.9 & .085 \\
\hline Wound problem/infection/pain ${ }^{\text {b }}$ & 5.7 & 14.6 & .049 \\
\hline PTOA $^{b}$ & NA & 20.4 & 1.00 \\
\hline Amputation $^{\mathrm{b}}$ & 0 & 0.08 & 1.00 \\
\hline
\end{tabular}

N/A, not applicable

aExpressed as mean ( \pm SEM)

bexpressed as percentage 


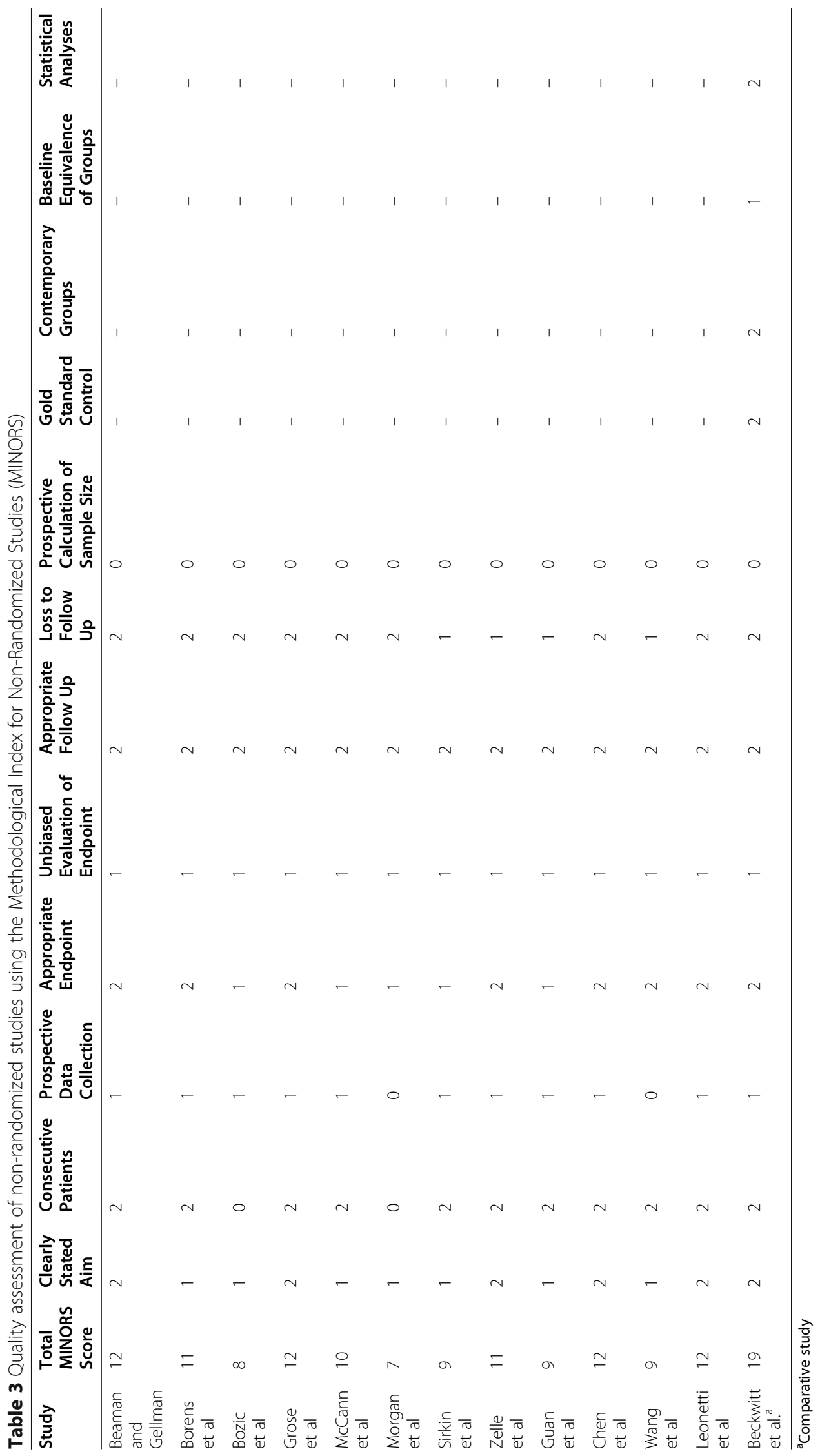


fusion of comminuted tibial plafond fractures, and with a two-year follow-up reported no wound complications and only one incidence of nonunion. Bozic et al. [8] treated 15 severely comminuted AO 43-C3 fractures with primary tibiotalar arthrodesis using a fixed-angle blade plate, achieving ankle fusion at an average of 15 weeks (range, 10-21). No patient required secondary procedures to obtain union. Similar results had previously been reported by Morgan et al. [21] in a series of 6 patients, in which primary ankle fusion was obtained after a mean of 26 weeks (range, 20-34), without any reported incidences of malunion or nonunion. The rates of malunion and nonunion are crucial aspects of this discussion, as they are among the most consequential complications of complex tibial pilon fractures. The individual rates from these studies as well as our qualitative synthesis suggest promising results for arthrodesis so far in this regard with a $2.9 \%$ rate compared to $9.9 \%$ in the staged ORIF group. However, given the limited numbers in the available literature (only two reported nonunions among patients treated with arthrodesis from the studies included in this review), further investigation of the difference in rates of nonunion and malunion is warranted, particularly with regards to infectious versus noninfectious causes.

In a retrospective study of 63 patients, Beaman and Gellman [20] reported on the outcomes of 13 patients treated over 2 years, whose highly comminuted tibial pilon fractures were treated with primary arthrodesis. The authors, who chose fusion based on clinical experience, theorized that primary ankle arthrodesis would expedite the patients' recovery and return to regular activity and improve clinical outcomes without the need for multiple procedures and long recovery times, as required with a staged approach. In their series, they were able to support their assumption with a high healing rate and good overall American Orthopaedic Foot and Ankle Society (AOFAS) functional score of 83 [34]. These findings are compatible with the functional score seen after ankle arthrodesis for osteoarthritis. Similar results were published by Zelle et al. [22], who retrospectively reviewed 20 patients, all with $\mathrm{AO}$ 43-C3 fractures treated over a period of 17 years with primary arthrodesis. Their results were comparable to those of other primary arthrodesis studies, with very low soft tissue complication and nonunion rates and acceptably good outcomes, with all patients able to ambulate without assistive devices. These latest findings complement the outcome published by Hendrickx et al. [35] in 2011, who studied 66 ankle arthrodesis cases performed for various indications at a mean follow-up of 9 years. The authors found that $91 \%$ of their patients were satisfied with their achieved ankle condition, with an AOFAS score of $67 \pm 12$ and an improved mental health perception according to the SF-36 score [35]. On the basis of their findings, they suggested that ankle arthrodesis improves the quality of life for patients with end stage ankle osteoarthritis.

\section{PICO question 2: long-term complications}

Poor outcomes of pilon fractures is associated with the extent of articular surface involvement and cartilage damage and quality of the anatomical reduction of the fracture fragments $[3,8,33,36-38]$. This point has been highlighted by Anderson et al. [36] and Marsh et al. [38], who emphasized the high incidence (up to 50\%) of PTOA secondary to fractures of the distal tibial articular surface. Both studies reported a strict correlation $(P<.01)$ between the development of PTOA and the high-energy injury and fracture pattern, with a 20 -fold higher risk of developing osteoarthritis within 2 years after high-energy pilon fractures. Similarly, Horisberger et al. [37] addressed the link between the development of PTOA and ankle fracture pattern with significantly shorter osteoarthritis latency time $(P<.01)$ in highly comminuted pilon fractures. Such articles emphasize the importance of evaluating the degree of articular surface damage because it can indicate a probable poor outcome.

Unfortunately, much of the literature reviewed in this study lacks long-term data needed to assess for the development of these outcomes. Among cases involving a staged treatment protocol, the average follow-up period was 26 months (range, 9-36). This number was significantly greater in the primary arthrodesis cohort, with an average follow-up time of 60 months (range, 24-86). Follow-up length is especially important when considering outcomes like PTOA, secondary arthrodesis, and amputation because these developments are typically observed with medium- or long-term follow-up. Most of the staged approach studies reviewed focused on shortor medium-term outcomes and thus did not adequately address long-term outcomes, especially arthrosis development. On the basis of the review of staged procedure articles, with reported PTOA rates of 20 to $50 \%$, the authors estimate the rate of secondary arthrodesis in patients with comminuted pilon fractures to be higher than the data reported in more recent series (8 to 20\%) $[3,15,26-29]$ as most of these studies had inadequate follow-up, an issue commonly seen in trauma populations [39]. No PTOA is expected in the primary arthrodesis group, as this complication is avoided with the joint fusion procedure. Thus, on the basis of this review, no conclusions can be made regarding the comparison of PTOA long-term outcomes between arthrodesis and staged ORIF. 


\section{Limitations}

The conclusions of this study are restricted by certain limitations, however. The arthrodesis group had a substantially higher proportion of patients with C3-type fractures in comparison to the staged ORIF group, which may represent a possible selection bias from the included studies and must be considered in any interpretation of the pooled results. Additionally, orthopaedic literature can be biased toward reporting positive outcomes [12, 40-44]. To educate their peers, surgeons tend to report methods that have led to good results, whereas most failures are not reported [40]. As a result, a cursory review of the literature may suggest that these complicated fractures are characterized by good outcomes when in reality the outcomes are not as encouraging as described in previous studies [44-46]. As discussed above, the lack of long-term data also contributes to the limitations of this study. Finally, outcomes reporting was not homogeneous between the literature included in this review, further limiting the ability to consolidate data from multiple studies. Despite these limitations, the strengths of this study include the larger sample size permitted by the consolidation of multiple studies. Most studies in the literature are small studies or based at single institutions, leading a limited sample size. A pooled analysis is often the only way to generate larger sample sizes for populations with injuries as rare as AO 43-C3 pilon fractures.

\section{Recommendations}

Currently, staged ORIF is the recommended treatment for severely comminuted fractures of the tibial pilon, and although primary arthrodesis appears to be associated with lower morbidity and an acceptable success rate, the authors cannot make any definitive statement about the outcomes at present. The literature regarding outcomes of AO 43-C3 pilon fractures remains limited and lacks reports of long-term evaluation and PTOA, which can be difficult to evaluate with poor follow-up rates in trauma patients. Randomized clinical trials using universal and standardized reporting methods are needed to properly define the long-term outcomes and direct the care for these patients. On the basis of the available literature, similar studies should be performed for primary arthrodesis.

\footnotetext{
Abbreviations

PICO: population, intervention/exposure, comparison, outcomes; $\mathrm{AO} /$ OTA: Arbeitsgemeinschaft für Osteosynthesefragen/Orthopaedic Trauma Association; ORIF: open reduction and internal fixation; PTOA: post-traumatic osteoarthritis; PRISMA: Preferred Reporting Items for Systematic Reviews and Meta-Analyses; RCTs: randomized controlled trials; MINORS: methodological index for non-randomized studies; AOFAS: American Orthopaedic Foot and Ankle Society
}

Acknowledgments

Not applicable.

\section{Authors' contributions}

E.A.H. designed this systematic review. Y.P.C., E.P., and H.H. performed the literature search and analysis of the data. Y.P.C. and E.A.H. drafted and wrote the final manuscript. P.F.S. was involved in the design and assisted revising the final manuscript. All authors read and approved the final version of this article.

\section{Funding \\ There were no external funding sources for this study.}

Availability of data and materials

Please contact the corresponding author for data requests.

\section{Declarations}

\section{FDA clearance}

Not applicable.

Ethics approval and consent to participate

Not applicable for a systematic review of the literature.

Consent for publication

Not applicable for a systematic review of the literature.

\section{Competing interests}

The authors declare no conflict of interest related to this study.

\section{Author details}

${ }^{1}$ Department of Orthopaedic Surgery, Philadelphia College of Osteopathic Medicine, Philadelphia, PA 19131, USA. ²Department of Specialty Medicine, Rocky Vista University, College of Osteopathic Medicine, Parker, CO 80134, USA. 'Department of Orthopaedic Surgery, The Johns Hopkins University, Johns Hopkins Bayview Medical Center, 4940 Eastern Ave. \#A667, Baltimore, MD 21224, USA

Received: 8 April 2021 Accepted: 25 May 2021

Published online: 18 October 2021

\section{References}

1. Boraiah S, Kemp TJ, Erwteman A, Lucas PA, Asprinio DE. Outcome following open reduction and internal fixation of open pilon fractures. J Bone Joint Surg Am. 2010;92(2):346-52. https://doi.org/10.2106/JBJS.H.01678.

2. Blauth M, Bastian L, Krettek C, Knop C, Evans S. Surgical options for the treatment of severe tibial pilon fractures: a study of three techniques. J Orthop Trauma. 2001;15(3):153-60. https://doi.org/10.1097/00005131-200103 000-00002.

3. Borens $\mathrm{O}$, Kloen P, Richmond J, Roederer G, Levine DS, Helfet DL. Minimally invasive treatment of pilon fractures with a low profile plate: preliminary results in 17 cases. Arch Orthop Trauma Surg. 2009;129(5):649-59. https:// doi.org/10.1007/s00402-006-0219-1.

4. Muller ME, Allgower M, Schneider R, Willenegger H. Manual of internal fixation: techniques recommended by the AO-ASIF Group. 3rd ed. New York: Springer-Verlag; 1991. https://doi.org/10.1007/978-3-662-02695-3.

5. Martin JS, Marsh JL, Bonar SK, DeCoster TA, Found EM, Brandser EA. Assessment of the AO/ASIF fracture classification for the distal tibia. J Orthop Trauma. 1997;11(7):477-83. https://doi.org/10.1097/00005131-19971 0000-00004

6. Marsh JL, Slongo TF, Agel J, Broderick JS, Creevey W, DeCoster TA, et al. Fracture and dislocation classification compendium - 2007: Orthopaedic trauma association classification, database and outcomes committee. J Orthop Trauma. 2007;21(10 Suppl):S1-S133. https://doi.org/10.1097/ 00005131-200711101-00001.

7. Orthopaedic Trauma Association Committee for Coding and Classification. Fracture and dislocation compendium. J Orthop Trauma. 1996;10:v-154.

8. Bozic $V$, Thordarson DB, Hertz J. Ankle fusion for definitive management of non-reconstructable pilon fractures. Foot Ankle Int. 2008;29(9):914-8. https:// doi.org/10.3113/FAl.2008.0914.

9. Matthews S. (iii) fractures of the tibial pilon. Orthop Trauma. 2012;26(3):1715. https://doi.org/10.1016/j.mporth.2012.06.004.

10. Liporace FA, Yoon RS. Decisions and staging leading to definitive open management of pilon fractures: where have we come from and where are 
we now? J Orthop Trauma. 2012;26(8):488-98. https://doi.org/10.1097/BOT. 0b013e31822fbdbe.

11. Mauffrey C, Vasario G, Battiston B, Lewis C, Beazley J, Seligson D. Tibial pilon fractures: a review of incidence, diagnosis, treatment, and complications. Acta Orthop Belg. 2011;77(4):432-40.

12. Thordarson DB. Complications after treatment of tibial pilon fractures: prevention and management strategies. J Am Acad Orthop Surg. 2000;8(4): 253-65. https://doi.org/10.5435/00124635-200007000-00006.

13. Ketz J, Sanders R. Staged posterior tibial plating for the treatment of Orthopaedic trauma association $43 \mathrm{C} 2$ and $43 \mathrm{C} 3$ tibial pilon fractures. J Orthop Trauma. 2012;26(6):341-6. https://doi.org/10.1097/BOT.0b013e31822 5881a.

14. Patterson MJ, Cole JD. Two-staged delayed open reduction and internal fixation of severe pilon fractures. J Orthop Trauma. 1999;13(2):85-91. https:// doi.org/10.1097/00005131-199902000-00003.

15. Sirkin M, Sanders R, DiPasquale T, Herscovici D Jr. A staged protocol for soft tissue management in the treatment of complex pilon fractures. J Orthop Trauma. 2004;18(8):S32-S8. https://doi.org/10.1097/00005131-20040900100005.

16. Moher D, Liberati A, Tetzlaff J, Altman DG, Group P. Preferred reporting items for systematic reviews and meta-analyses: the PRISMA statement. PLoS Med. 2009;6(7):e1000097. https://doi.org/10.1371/journal.pmed.1 000097.

17. Huang $X$, Lin J, Demner-Fushman D, editors. Evaluation of PICO as a knowledge representation for clinical questions. AMIA annual symposium proceedings; 2006: American Medical Informatics Association.

18. Ruedi TP, Allgower M. Fractures of the lower end of the tibia into the anklejoint. Injury. 1969; 1 (2):92-9. https://doi.org/10.1016/S0020-1383(69)80066-5.

19. Slim K, Nini E, Forestier D, Kwiatkowski F, Panis Y, Chipponi J. Methodological index for non-randomized studies (MINORS): development and validation of a new instrument. ANZ J Surg. 2003;73(9):712-6. https:// doi.org/10.1046/j.1445-2197.2003.02748.x.

20. Beaman DN, Gellman R. Fracture reduction and primary ankle arthrodesis: a reliable approach for severely comminuted tibial pilon fracture. Clin Orthop Relat Res. 2014;472(12):3823-34. https://doi.org/10.1007/s11999-014-3683-x.

21. Morgan SJ, Thordarson DB, Shepherd LE. Salvage of tibial pilon fractures using fusion of the ankle with a 90 degrees cannulated blade-plate: a preliminary report. Foot Ankle Int. 1999;20(6):375-8. https://doi.org/10.11 77/107110079902000606.

22. Zelle BA, Gruen GS, McMillen RL, Dahl JD. Primary arthrodesis of the tibiotalar joint in severely comminuted high-energy pilon fractures. J Bone Joint Surg Am. 2014;96(11):e91. https://doi.org/10.2106/JBJS.M.00544.

23. Beckwitt CH, Monaco SJ, Gruen GS. Primary ankle arthrodesis vs ORIF for severely comminuted Pilon fractures. Foot Ankle Orthopaedics. 2018;3(3): 247301141878043. https://doi.org/10.1177/2473011418780437.

24. Chen H, Cui X, Ma B, Rui Y, Li H. Staged procedure protocol based on the four-column concept in the treatment of AO/OTA type 43-C3.3 pilon fractures. J Int Med Res. 2019;47(5):2045-55. https://doi.org/10.1177/03 00060519836512

25. Guan J, Huang M, Wang Q, Chen Y, Wang L. Treatment of AO/OTA 43-C3 Pilon fracture: be aware of posterior column Malreduction. Biomed Res Int. 2019;2019:1-7.

26. Wang Z, Qu W, Liu T, Zhou Z, Zhao Z, Wang D, et al. A two-stage protocol with vacuum sealing drainage for the treatment of type $C$ Pilon fractures. The J Foot Ankle Surg. 2016;55(5):1117-20. https://doi.org/10.1053/j.jfas.2016. 01.047.

27. Leonetti $D$, Tigani D. Pilon fractures: a new classification system based on CTscan. Injury. 2017;48(10):2311-7. https://doi.org/10.1016/j.injury.2017.07.026.

28. Grose A, Gardner MJ, Hettrich C, Fishman F, Lorich DG, Asprinio DE, et al. Open reduction and internal fixation of tibial pilon fractures using a lateral approach. J Orthop Trauma. 2007;21(8):530-7. https://doi.org/10.1097/BOT. Ob013e318145a227.

29. McCann PA, Jackson M, Mitchell ST, Atkins RM. Complications of definitive open reduction and internal fixation of pilon fractures of the distal tibia. Int Orthop. 2011;35(3):413-8. https://doi.org/10.1007/s00264-010-1005-9.

30. Davidovitch Rl, Elkataran R, Romo S, Walsh M, Egol KA. Open reduction with internal fixation versus limited internal fixation and external fixation for high grade pilon fractures (OTA type 43C). Foot Ankle Int. 2011;32(10):955-61. https://doi.org/10.3113/FAl.2011.0955.
31. Hsu AR, Szatkowski JP. Early Tibiotalocalcaneal arthrodesis intramedullary nail for treatment of a complex Tibial Pilon fracture (AO/OTA 43-C). Foot Ankle Specialist. 2015;8(3):220-5. https://doi.org/10.1177/1938640014548322.

32. White TO, Guy P, Cooke CJ, Kennedy SA, Droll KP, Blachut PA, et al. The results of early primary open reduction and internal fixation for treatment of OTA 43.C-type tibial pilon fractures: a cohort study. J Orthop Trauma. 2010; 24(12):757-63. https://doi.org/10.1097/BOT.0b013e3181d04bc0.

33. Calori GM, Tagliabue L, Mazza E, de Bellis U, Pierannunzii L, Marelli BM, et al. Tibial pilon fractures: which method of treatment? Injury. 2010;41(11):118390. https://doi.org/10.1016/j.injury.2010.08.041.

34. Kitaoka HB, Alexander IJ, Adelaar RS, Nunley JA, Myerson MS, Sanders M. Clinical rating systems for the ankle-hindfoot, midfoot, hallux, and lesser toes. Foot Ankle Int. 1994;15(7):349-53. https://doi.org/10.1177/1071100794 01500701.

35. Hendrickx RPM, Stufkens SAS, de Bruijn EE, Sierevelt IN, van Dijk CN, Kerkhoffs GMMJ. Medium- to long-term outcome of ankle arthrodesis. Foot Ankle Int. 2011;32(10):940-7. https://doi.org/10.3113/FAl.2011.0940.

36. Anderson DD, Chubinskaya S, Guilak F, Martin JA, Oegema TR, Olson SA, et al. Post-traumatic osteoarthritis: improved understanding and opportunities for early intervention. J Orthop Res. 2011;29(6):802-9. https:// doi.org/10.1002/jor.21359.

37. Horisberger M, Valderrabano V, Hintermann B. Posttraumatic ankle osteoarthritis after ankle-related fractures. J Orthop Trauma. 2009;23(1):60-7. https://doi.org/10.1097/BOT.0b013e31818915d9.

38. Marsh JL, Weigel DP, Dirschl DR. Tibial plafond fractures. How do these ankles function over time? J Bone Joint Surg Am. 2003:85(2):287-95. https:// doi.org/10.2106/00004623-200302000-00016

39. Zelle BA, Buttacavoli FA, Shroff JB, Stirton JB. Loss of follow-up in Orthopaedic trauma. J Orthop Trauma. 2015;29(11):510-5. https://doi.org/1 0.1097/BOT.00000000000000346.

40. Ezzet KA. The prevalence of corporate funding in adult lower extremity research and its correlation with reported results. J Arthroplasty. 2003;18(7 (Suppl 1)):138-45.

41. Harris IA, Mourad M, Kadir A, Solomon MJ, Young JM. Publication bias in abstracts presented to the annual meeting of the American Academy of Orthopaedic surgeons. J Orthop Surg (Hong Kong). 2007;15(1):62-6. https:// doi.org/10.1177/230949900701500114.

42. Hasenboehler EA, Choudhry IK, Newman JT, Smith WR, Ziran BH, Stahel PF. Bias towards publishing positive results in orthopedic and general surgery: a patient safety issue? Patient Saf Surg. 2007;1(4):1-6.

43. Lynch JR, Cunningham MR, Warme WJ, Schaad DC, Wolf FM, Leopold SS. Commercially funded and United States-based research is more likely to be published; good-quality studies with negative outcomes are not. J Bone Joint Surg Am. 2007:89(5):1010-8. https://doi.org/10.2106/JBJS.F.01152.

44. Watson JT, Moed BR, Karges DE, Cramer KE. Pilon fractures. Treatment protocol based on severity of soft tissue injury. Clin Orthop Relat Res. 2000; 375:78-90. https://doi.org/10.1097/00003086-200006000-00010.

45. Pollak AN, McCarthy ML, Bess RS, Agel J, Swiontkowski MF. Outcomes after treatment of high-energy tibial plafond fractures. J Bone Joint Surg Am. 2003;85(10):1893-900. https://doi.org/10.2106/00004623-200310000-00005.

46. Bacon S, Smith WR, Morgan SJ, Hasenboehler E, Philips G, Williams A, et al. A retrospective analysis of comminuted intra-articular fractures of the tibial plafond: open reduction and internal fixation versus external Ilizarov fixation. Injury. 2008;39(2):196-202. https://doi.org/10.1016/j. injury.2007.09.003.

\section{Publisher's Note}

Springer Nature remains neutral with regard to jurisdictional claims in published maps and institutional affiliations. 